\title{
Simulating Professional Practice in STEAM Education: A Case Study
}

\author{
Sarah Lugthart ${ }^{1 *}$, Michel van Dartel ${ }^{1}$ \\ 1 Avans Centre of Applied Research for Art, Design \& Technology (CARADT), NETHERLANDS
}

*Corresponding Author: sm.lugthart@avans.nl

Citation: Lugthart, S. and van Dartel, M. (2021). Simulating Professional Practice in STEAM Education: A Case Study. European Journal of STEM Education, 6(1), 17. https://doi.org/10.20897/ ejsteme/11393

Published: December 1, 2021

\begin{abstract}
Situated learning could benefit STEAM education because both aim to develop skills that can deal with complex real-life situations. Although ample research has been conducted into situated learning within higher vocational education in general, there exists little research on the implementation of the educational approach in STEAM education specifically. To gain insight into what is needed for this implementation, a case study of a situational simulation was conducted within a STEAM education context, in which we observed students in simulating media design studios. We observed the setup, working and evaluation phases of the simulation and analyze the data this yielded - setup surveys, studio agreements, feedback forms, individual reflections and concluding surveys - based on three core features of situated learning: community of practice, participation and authentic context. Based on this analysis, we conclude that our study confirms the potential of situated learning for STEAM education. Our case study also suggests four guidelines for, as well as one challenge in, the implementation of situated learning in STEAM education. These guidelines and challenge are 1.) to actively facilitate quality feedback between students within a situational simulation; 2.) to promote taking various professional roles within the simulation, 3.) to provide situational-specific scaffolding based on the determination of which skills and information should be offered by tutors and which skills and information students already possess or are best left to develop and find by themselves; and 4.) to gain insight into individual learning goals for the benefit of the cognitive realism of the simulation; while 5.) the absence of real financial or commercial consequences compromises the authenticity of a situational simulation and, consequently, challenges the implementation of situated learning in STEAM education.
\end{abstract}

Keywords: situated learning, media design education, authentic learning, learning environments, situational simulation

\section{INTRODUCTION}

Situated learning has been advocated as a valuable educational approach for STEM education (Asunda, 2014). The approach might arguably also benefit STEAM education, as both STEAM education and situated learning aim to develop skills that can deal with complex real-life situations and collaborative environments (Daugherty, 2013; Guyotte et al., 2015). Similar to educational approaches like constructivism (Kafai, 2006), connectivism (Griffiths and Guile, 2003), problem-based learning (Barrett, 2010) and authentic learning (Roach, 2018), situated learning is focused on providing learning experiences that occur through the social interaction and kinesthetic activity of reallife activities in the context of a prospective practice or related tasks (Northern Illinois University Center for Innovative Teaching and Learning, 2012). STEAM education does not only typically focus on design thinking and fostering imagination and creativity to approach real-world problems in an innovative way (Cruz et al., 2021; 
Daugherty, 2013), but can also be characterized as incorporating "studio habits of mind as an experience-based technique for problem solving, learning, investigation, and discovery" (Daugherty, 2013, p.12). Additionally, Guyotte et al. (2015) question the notion of the 'lone artist' working in their studio, stressing the collaborative aspect of STEAM within inter- or transdisciplinary practices. Just as the above-mentioned situated learning approach does, the design challenges that are common within STEAM education aim for the learning of skills by working on real-world problems in a collaborative setting.

Given this kinship between situated learning and STEAM it is surprising that there exists little research on the implementation of the educational approach in STEAM education specifically, while ample research has been conducted into situated learning within higher vocational education in general (see, e.g., Choi and Hannafin, 1995; Herrington and Oliver, 2000; or Shaltry et al., 2013). The domain of media design consists of the creative interdisciplinary practices typical of STEAM, even though it "involves the physical, functional, and operational manifestation of human-factors design" (Garson and Khosrowpour, 2007, p. 661) that are often associated with STEM. Within STEAM, media design is typical for its use of studios as a common organizational form, in which so-called soft skills (i.e., artistic, design, communication and collaborating skills) are just as important as so-called hard skills (i.e., knowledge of hardware and production pipelines) (Vyas et al., 2012). As a result, media design education offers an ideal context to come to a better understanding of how situated learning, i.e., learning by participating in activities that replicate actual work settings (Northern Illinois University Center for Innovative Teaching and Learning, 2012), should be implemented within STEAM education.

Therefore, we formulated the following research question: How could situated learning be implemented within STEAM education? To answer this research question, we conducted a case study in which students were monitored during the setup, working and evaluation phases of a situational simulation in STEAM education and surveyed after completing the simulation to evaluate their experiences.

In the below, we will first briefly discuss how the principles of situated learning relate to STEAM education, before we present our case study in more detail. We will subsequently present our results and discuss them, to then conclude on that discussion by offering guidelines for the implementation of situated learning within STEAM education and identifying a challenge to this implementation.

\section{BACKGROUND}

Since researchers have become aware of the limitations of traditional classroom instructions, educational approaches which promote learning that connects to real-life experiences have gained more and more attention. Situated learning is such an approach and is based on the view that "meaningful learning will only take place if it is embedded in the social and physical context within which it will be used" (Herrington and Oliver, 1995, p. 254). According to Donaldson and Barany (2019) situated learning has three core features: communities of practice, participation, and authentic context.

The first core feature of situated learning, communities of practice, refers to the sociocultural specificity of a community of practitioners, i.e., groups that form around shared patterns of behavior. In the domain of media design, such shared patterns of behavior can for instance be observed in a design studio: since the work is collaborative in nature, the studio space offers typical ways in which material artefacts, inspiration, storyboards and sketches are shared, as well as in which discussion and critique are facilitated. Communication with clients, including the typical practice of 'pitching' projects to clients, also is a typical facet of design studio practice. Hence, the shared patterns of behavior typical for a community of practice are not only related to 'hard skills' (i.e., technical skills); they also form around 'soft skills' (i.e., the interpersonal skills required to perform a role) that are typical for a practice. To learn the patterns of behavior within a community of design practitioners, learners require access to real-world practices within design studios. This access requires that the school invests in building a network of partners in the field, to ensure a strong connection with the practice (Wesselink et al., 2010).

The second core feature of situated learning, participation, refers to if and how students are encouraged to explore which roles or activities inside a community of practice fit their talents and skills best. Within media design schools, students are introduced to the complete process of design, from idea generation and concept to producing a project; but also to specific roles, like being a director, storyboard artist, concept artist or producer. In the practice of media design, it is important to have clear overview of the whole production process, yet it is also common to specialize in a certain area of expertise or in one or more roles within the practice. Therefore, providing experience with these areas of expertise and roles is vital to prepare students for a professional career in media design. Scaffolding may be required to support a learner in the transition from newcomer to full participant through participation in a community (Donaldson and Barany, 2019). Where and when to provide this scaffolding is particularly challenging within situated learning environments, since "any preplanning in this context makes a mockery out of the learning outcomes" (Roach et al., 2018, p. 498). According to Herrington and Oliver (1995), 
the role of the teacher should be integral in situated learning environments, and the coaching and scaffolding they provide should always be timely and situation-specific.

The third core feature of situated learning is authentic context, i.e., "robust, complex, social environments made up of actors, actions, and situations" (Stein, 1998, p. 2). As "learning context and the activities within that context are meaningful [in providing] the opportunities necessary to solve problems practically so they can transfer those competencies to real-world experiences" (DiSchiavi, 2019), authentic contexts may help bridge the gap between (studying in) a school environment and (working in) a real-life practice. Such learning environments should also be cooperative in nature, to add to the authenticity of the (learning) environment by enhancing social interaction and enabling learners to build on experiences together (NIU-CITL, 2012).

Typical examples of situated learning experiences usually take place outside of the school environment, i.e., field trips or internships. However, the possibilities to benefit from situated learning principles within the school context, e.g., in the form of educational simulations, have extensively been explored since the 80s (Lunce, 2006; Herrington, 2015; Roach et al., 2018). Within educational simulations, the student buy-in is vital. To achieve this, the cognitive realism of the simulation is more important than its physical realism and the assignments should be of value for the student as much as for the community of practice (Roach et al, 2018).

Because of its open-ended design and the complexity of modelling real-life situations inside a school environment, Lunce (2006) argues that a situational simulation "is the most difficult type of simulation to design and to utilize effectively." Referring to scientific and engineering simulations, designing simulations arguably are particularly complex for simulations that involve computer programming. In the context of media design, creating a realistic framework that does justice to the complexity of real-life practice is arguably even made more difficult by the 'wicked problems' that many such designers work on (Donaldson and Barany, 2019).

The above suggests that four factors need to be taken into account in the implementation of the three core features of situated learning in a school environment: 1.) the implementation requires a strong partner-network that can provide access to a community of practice; 2.) the student collaboration in the (simulated) real-world practice should allow for freedom to explore different roles and identities; 3 .) coaches should provide situationspecific scaffolding; and 4.) a high level of cognitive realism can be achieved when the (simulated) assignments are of value to the learner and the community of practice.

In the next section, we will introduce a case study titled Project Soho that was conducted to provide more insight into how these four factors influence the implementation of the three features of situated learning in the creative interdisciplinary practices typical of STEAM education.

\section{CASE STUDY: PROJECT SOHO}

Every year, students of the Master Animation of the Master Institute of Visual Cultures (MIVC, The Netherlands) participate in a situational simulation called Project Soho. In Project Soho, groups of students simulate media design studios modelled after the animation studios that are situated in close proximity to each other in the neighborhood of Soho, the bustling creative heart of London. The aim of the simulation is to familiarize students with the hard and soft skills that an animation studio requires and to discover what their preferred role in the creative practice of animation might be. Potential clients in the network of the school are contacted with the request to participate and provide a realistic briefing. Before determining their realistic assignments, clients receive information about the aims of Project Soho and what is expected of clients in the process. They are for instance expected to provide a contact person for questions by students and to be available to meet with the students for the brief (setup phase), pitch (working phase) and final presentation (evaluation phase) of the project.

\section{Method}

At the start of the simulation, four or five students are grouped together to form a design studio: tutors form groups on the basis of the roles that students prefer and make sure that the soft and hard skills required to operate an animation studio are represented within each group. The studios themselves can still decide on how they will divide the roles per assignment. The studios then start their work on realistic assignments for real clients. Although students do not receive financial compensation for their work, their studios are required to provide clients with a realistic budget for the assignments and discuss these budgets with their clients. The assignments are diverse in the level of creative freedom they allow as well as in their envisioned results: they may range from creating the title sequence for a festival or short (online) idents to celebrate the anniversary of a national film institute, to creating 3D characters for an immersive experience or a commercial to promote a smartphone app. The realistic design briefs describing the assignments are sent to the main contact of each studio in varying intervals throughout the simulation. In response to receiving a briefing, studios can either accept or reject an assignment, based on their studio profile, planning and learning goals. 
Scaffolding is provided by tutors on a weekly basis and upon request also by experts in the field. In such scaffolding, tutors and coaches typically discuss aspects and issues related to the organization of their work (e.g., how to streamline the production pipeline) and to the interpretation of roles (e.g., what the tasks and responsibilities of a certain professional role are).

\section{Participants and Duration}

The case study involved 22 master students (participants), with backgrounds ranging from communication and media design to graphic design and animation backgrounds. Some of them had more training within the visual arts, like illustration, while others had experience with programming and interaction design. The study was conducted over a period of eight weeks, in which three phases of simulation occurred: setup, working, and evaluation.

\section{Data Collection}

During the setup phase, a setup survey was distributed amongst the participants to assess their expectations of Project Soho for the purpose of our study. The survey also served to make an inventory of their preferences for a professional role within the simulation, the skills and experience they would bring into the studio and their personal learning goals. Participants could opt for multiple roles, since they would work on multiple projects and could redivide roles within each of them. After grouping the students into studios on the basis of this data, each studio was requested to set up an agreement on how they would work together: including a description of the studio's identity and working hours, the frequency of internal meetings, the division of roles within the studio and how potential internal disputes would be settled should they occur. For the purpose of our study, copies of all studio agreements were also collected during the setup phase.

In the working phase of the simulation, feedback forms were collected that were modeled after the 360 degrees feedback method (Kaya et al., 2016), in which studio members were asked to provide each other with feedback regarding their individual performance within the studio. Participants were asked to fill in these forms once halfway the simulation and once at its end.

In the evaluation phase, copies of individual reflections were collected. Participants were asked to reflect on what they learned during the simulation, based on the feedback given in the feedback forms and including any actions that were taken in response. Furthermore, an online concluding survey was held under participants after the simulation finished. This survey provided data on the experiences of participants with the 'community of practice' (questions 1 to 5); of their 'participation' in that community (question 6 and 7); and of the 'authentic context' in which they participated (question 8). Question 1,2, 5 and 6 were multiple choice questions, while questions 3, 4, 7 and 8 provided open ended questions.

In the next section, we will present the data yielded by our case study and analyze it based on the three core features of situated learning: community of practice, participation and authentic context.

\section{RESULTS \& DISCUSSION}

During the setup phase, 21 participants filled in a setup survey: one participant failed to submit a survey. In the survey, five participants expressed a desire to explore the role of 'producer'. However, the most popular role according to our survey, was that of '(art) director': exploring this role in the simulation was desired by 15 participants. Other roles that were mentioned were $2 \mathrm{D}$ animator (twelve times), character designer (eight times), storyboard artist (six times), and 3D animator (four times). Subsequently, tutors compiled five groups of participants to form simulated animation design studios, based on the skills that students indicated they possessed in the survey, by for instance equally dividing $2 \mathrm{D}$ and $3 \mathrm{D}$ skills over the groups. It is important to note here that more participants expressed a desire to explore the role of director than the number of groups that were formed.

In the setup phase, students attended presentations by media design industry professionals, in which they were introduced to the various roles and responsibilities within a media design studio (e.g., storyboard artist, lead animator, technical director, creative director and producer). Afterwards, the groups (studios) were asked to develop their studio identity, work on a studio agreement and provide contact information for clients. This resulted in five studio identities (Anymate (five members), Beehive (four members), Mixmax (four members), Multiki (five members) and MXR (four members)) and yielded five copies of studio agreements. Each of the five studios were provided with a designated workspace in the school. Based on the studio agreements they developed, studio members both worked at school and from their homes during the working phase. During this phase, five client briefings were distributed amongst all five studios. All studios excepted at least three of these assignments. The working phase of our study yielded 22 feedback forms.

Finally, the evaluation phase yielded 21 individual reflections and 16 concluding surveys. 
The next subsections will analyze the setup surveys, studio agreements, feedback forms, individual reflections and concluding surveys based on the three core features of situated learning: community of practice, participation and authentic context.

\section{Community of Practice}

In section 2, we introduced the importance of a strong partner-network for access to typical patterns of behavior of a community of practice.

In the concluding survey all of the respondents answered 'yes' to question 1: 'Did project Soho provide you with insights into the practice of animation studios?' Most of them ( $87.5 \%)$ responded positive to question 2: 'Did you learn about typical ways of working and collaborating that take place within such animation studios?' One respondent answered: 'not more than I already knew'. Another respondent was 'not sure'. When asked to mention any 'hard skills' (i.e., technical skills, like using software) that they learned (question 3), nine respondents mentioned specific software (Toon Boom, C4D and $A E$ ) and five mentioned folder structure/pipeline organization (i.e., how to organize a production). Storytelling skills were only mentioned once ('how to work with a storyboard and animatic'). When asked about 'soft skills' (question 4), answers ranged from learning about how to pitch and communicate with clients, to more personal skills such as giving feedback and gaining confidence. One respondent said: "I learned more about meetings with clients (debriefing, listening, pitching) and I also learned the importance of good communication within the studio, setting realistic expectations for everyone and how to plan better."

In their individual reflections, three participants explicitly mentioned that they normally work by themselves. Resultantly, the soft skills that are important to collaborate effectively were often mentioned in the individual reflections. A member of Beebive for instance wrote: "The period overall demonstrated the value of working as a team to me. I am used to working by myself, but hearing different ideas from other members and combining them into one resulted in concepts that positively surprised me." The lack of experience in working together as a team also shows in the discomfort that participants experienced with respect to providing feedback to fellow members, which eight participants reported in the individual reflections. A member of Anymate for instance wrote: "Quite often I felt a bit bad to share an opinion. I was scared to come across pushy and bossy. Now, in the feedback forms, I see everyone appreciated my feedback, on the basis of which I conclude that I did show respect towards them and [giving feedback is part of having] a good conversation about the work." Similarly, a member of Beehive mentioned: "We initially experienced uncertainties about the concept and unclarity about who was taking the lead. At this time, I was afraid to say what I was thinking as it could hurt the feelings of other members. Now I would behave differently in that situation."

When asked 'Did the experience provide you with access to the professional field? E.g., did you develop your professional network?' $50 \%$ of the respondents answered this question positively. The other $50 \%$ were 'not sure' if the course resulted in better access to the professional field and was beneficial to their development of a professional network (question 5). This outcome may have been influenced by the effect that the COVID19pandemic had on the balance between working on- and offline.

\section{Participation}

Besides the importance of a strong partner-network for access to typical patterns of behavior of a community of practice, in section 2, we also introduced the importance of exploring roles and identities for the implementation of participation in a community of practice and emphasized the need for timely and situation-specific scaffolding as part of it.

The individual reflections that our case study yielded in particular demonstrated the value of the exploration of professional roles within the simulations. A member of Anymate for instance commented: "Being an art director really opened my eyes. In my mind, the role of art director was so much smaller than I experienced it to be. There is so much one needs to take into account as a director!" Another perspective on the value of the explorations of different roles is expressed by a member of MXR: "Because I switched roles, I now understand better what art directors and animators expect from each other."

The individual reflections also showed that the exploration of various roles only confirmed the expectations of some participants, while for others it did the opposite. A member of MXR for instance wrote: "I am a natural leader and like to keep an overview of everything, so I was interested in taking up the role of producer. [Project] Soho was perfect for me to try it and I learned that the role indeed suits me." A member of Beebive experienced the opposite: "Working on three projects at the same time has taught me that the role of producer is not for me. It has been valuable [to experience this role] nonetheless, as I gained insight into what it means to perform this role."

Besides demonstrating the value of exploring various professional roles within an educational simulation, our data also shows that in the development of professional careers, from novice to expert, it is important that participants learn by doing: by performing a professional role in the context of a (simulated) practice it becomes 
apparent what is expected from that role without explicit instruction (i.e., situated learning). The concluding survey showed that $93,8 \%$ of the respondents reported a better understanding of the profession: i.e., 'yes' to question 6 'Do you better understand what is expected from a professional in the field of animation after project Soho? For instance, how to communicate, work/produce and apply technical skills.' This is also supported by quotes from the individual reflections. A member of Mixmax commented: "I wanted to step out of my comfort zone, so I chose to be the art director [...]. This also meant pitching the idea to the client. This was very scary for me, yet in the end I started to like it more and more. I am a generalist and I look at the big picture of how different people and pieces fit together and what my place within that picture is. I noticed that this personality trait really helped me in directing."

At the same time however, the need for scaffolding in exploring professional roles was also expressed in the responses to the question (7) 'Looking back, were there specific moments during Project Soho in which you felt the need for more / better instructions by tutors or experts?' Some needs that were expressed in response to this question are related to planning skills. For instance, two respondents reported a need for more help in planning their work and two participants reported needs related to soft skills, such as giving constructive feedback. Five respondents expressed the need for more support in setting up and running their studios, by providing examples of studio agreements and budgets for instance. Also, seven participants mentioned the need for more clarity on how to engage with clients within the simulation (especially with respect to the financial agreements) and on what would happen with their design output.

\section{Authentic Context}

With respect to the authenticity of contexts in situational simulations, in section 2 we argued that a high level of cognitive realism can be achieved when (simulated) assignments are of value to both the learner as well as the community of practice as a whole.

The setup survey provided insights into the different roles that participants wanted to perform as part of the simulation, to make sure the roles they would be performing within it would be of value to them. Participants opting for the role of 'producer' were divided over the five studios, but most of the other roles required to complete an assignment were determined by the members when the client brief was received and accepted by the studio. In line with actual professional media design practice, the producer decided which team member was assigned which professional role and in many cases members were asked to fulfill multiple roles. In this sense, the simulation was authentic. However, since 15 participants expressed the desire to perform the role of (art) director, and there were not enough positions for art director available, it was not possible for all of those participants to perform this role. Even so, all participants with a desire to experience this role that could not perform it in the simulation, could perform another role they had expressed an interest in, resulting in the same or a similar value of their participation in the simulation.

The value for the community of practice is embodied in the design outcomes: with the exception of one outcome, all assignments resulted in products of which the client indicated that they could actually use them.

The concluding survey data suggests that a high level of cognitive realism was achieved: 10 out of 16 respondents answered question 8 positively: 'Was project Soho in your opinion authentic to the professional field of animation? I.e., did you experience its (physical) environment/setting, clients (type of clients/ contact with clients), working in team/ collaboration as studio as genuine?

Six out of 16 respondents answered 'almost' to question 8. Although one participant reported a lack of time spent inside the studio workspace ("Due to the pandemic we did not get to experience the [studio] environment that much.") this did not seem to hinder the authenticity of the simulation. As one participant mentioned: "My experience was similar to the real studio experiences that I had before, although those were not in animation. So, in my opinion it was quite realistic [...]. Of course, [on the basis of this experience] I still do not know how it is to work in a big studio for a long time."

Four out of the 16 respondents mentioned that working with 'mock' budgets affected the authenticity of the simulation. One respondent for instance mentioned: "It is almost real. But in terms of choosing which client we wanted to work with, we always chose the one we were interested in working with instead of the one who would pay [the most for our work]. If there would have been real money involved, we would have made different choices." The individual reflections also pointed this out: four participants reported to have learned what taking on or declining work means for the income of a studio, but without the pressure of actually having to financially survive as a studio. A member of MXR commented: "Another thing I learned is to choose the project wisely and be realistic. For example, a project that pays well or offers a chance to promote the studio often provides lesser creative freedom." This participant also indicated that the studio always opted for projects with the most creative freedom ("passion projects") as this decision would not have any (real) financial or commercial consequences. 


\section{CONCLUSIONS}

From the findings above, five conclusions can be drawn that answer to our research question: How could situated learning be implemented within STEAM education?

Our first conclusion is that access to a community of practice in a situational simulation should be implemented in STEAM education by actively facilitating quality feedback between students and that clients can play a role in providing insight into behavior typical for their community of practice. The patterns of behavior surrounding feedback between studio members in particular (both how it is received and ought to be processed) are crucial to learn how to become part of the community of practice. Being able to offer and receive quality feedback are vital skills within the media design practice (Evans, 2020; McDonald, 2020). Within our case study, participants mainly learned from each other's feedback. Yet, based on the reported experienced value of such feedback, it might be beneficial to also include client feedback as a way to learn to give or receive quality feedback. Clients should perhaps also be involved in providing access to what is typical behavior with respect to giving and receiving quality feedback.

Secondly, we conclude that the implementation of participation in STEAM education requires that participants can take up various roles within the situational simulation.

Our third conclusion is that the implementation of situated learning in STEAM education requires situationspecific scaffolding, which in turn requires the determination of which skills and information should be offered by tutors and which skills and information students already possess or are best left to develop and find by themselves. Providing scaffolding in the right place at the right time is difficult. Partly, because the needs for scaffolding can differ between students. Although additional scaffolding, such as providing examples of documents like studio agreement and budgets could make for better scaffolding, at least in this particular simulation, adding to the scaffolding always begs the question which skills and knowledge should be offered by tutors and which of them students already possess or best find out for themselves.

Fourthly, we conclude that the level of cognitive realism of a situational simulation in STEAM education may benefit from gaining insight into the individual learning goals of participants.

Finally, our fifth conclusion is that the implementation of authentic contexts in STEAM education may be compromised by the absence of real financial or commercial consequences in situational simulations. 'Mock' budgets may be in the way of making realistic decisions. These insights reveal an important clash between the aim to facilitate a high level of cognitive realism and the practical restrictions of the school context: a situational simulation should provide an authentic context by connecting to real clients, but that authenticity is compromised by the absence of real financial or commercial consequences.

As our case study focused on the creative interdisciplinary aspects of media design practices that are typical of STEAM education, it remains to be seen if these five conclusions also hold for STEM education, with which media design shares "the physical, functional, and operational manifestation of human-factors design" (Garson and Khosrowpour, 2007, p. 661).

Besides confirming the potential of situated learning for STEAM education, these five conclusions to our case study suggest four guidelines to the implementation of situated learning in STEAM education, as well as one challenge. These four guidelines and challenge are to 1.) actively facilitate quality feedback between students within a situational simulation; 2.) promote taking various roles within the simulation; 3.) provide situational-specific scaffolding based on the determination of which skills and information should be offered by tutors and which skills and information students already possess or best develop and find for themselves; and 4.) gain insight into individual learning goals for the benefit of the cognitive realism of the simulation; while 5.) the absence of real financial or commercial consequences may compromise the authenticity of a situational simulation and, consequently, forms a challenge to the implementation of situated learning in STEAM education.

\section{REFERENCES}

Asunda, P. (2014) A Conceptual Framework for STEM Integration Into Curriculum Through Career and Technical Education. Journal of STEM Teacher Education, 49(1), 3-15. https://doi.org/10.30707/ JSTE49.1Asunda

Barrett, T. and Moore, S. (Eds.). (2010). New approaches to problem-based learning. Revitalizing your practice in bigher education. Routledge. https://doi.org/10.4324/9780203846926

Choi, J. and Hannafin, M. (1995). Situated cognition and learning environments: Roles, structures, and implications for design. Educational Technology Research \& Development, 43, 53-69. https://doi.org/10.1007/BF02300472

Cruz, J., Bruhis, N., Kellam, N. and Jayasuriya, S. (2021). Students' implicit epistemologies when working at the intersection of engineering and the arts. Journal of STEM Education, 8, 29. https://doi.org/10.1186/s40594-02100289-w 
Daugherty, M. (2013). The Prospect of an "A" in STEM Education. Journal of STEM Education, 14(2), 10-15.

DiSchiavi, E. (2019, July 12). Applying theory to practice. Using technology to support situated cognition in education, in Technology and the Curriculum: Summer 2019. https://techandcurr2019.pressbooks.com/ chapter/situated-cognition-meaningful-learning-space/

Donaldson, J. and Barany, A. (2019). Designerly Ways of Learning, in Proceedings FabLearn 2019 Eighth Annual Conference, 50-56. https://doi.org/10.1145/3311890.3311897

Evans, J. (2020, March 21). Vital Soft Skills Every Successful Animator Needs To Have. Animatedjobs.com. Available at: https://animatedjobs.com/animationjobs/vital-soft-skills-every-successful-animator-needs-to-have/

Garson, G. and Khosrowpour, M. (2007). Handbook of Research on Public Information Tecbnology. Information Science Reference.

Griffiths, T. and Guile, D. (2003). A Connective Model of Learning: The Implications for Work Process Knowledge. European Educational Research Journal, 2(1), 56-73. https:// doi.org/10.2304/eerj.2003.2.1.10

Guyotte, K. W., Sochacka, N. W., Costantino, T. E., Kellam, N. N. and Walther, J. (2015). Collaborative creativity in STEAM: Narratives of art education students' experiences in transdisciplinary spaces. International Journal of Education \& the Arts, 16(15), 1-38.

Herrington, J. and Oliver, R. (1995). Critical characteristics of situated learning: Implications for the instructional design of multimedia, in ASCILITE 1995 Conference, 3-7 December 1995. Melbourne: University of Melbourne, 253-262.

Herrington, J. and Oliver, R. (2000). An instructional design framework for authentic learning environments. Education Technology Research and Development, 48, 23-48. https://doi.org/10.1007/BF02319856

Kafai, Y. B. (2006). Playing and making games for learning: Instructionist and constructionist perspectives for game studies. Games and Culture, 1(1), 36-40. https:/ / doi.org/10.1177/1555412005281767

Kaya, N., Aydin, S. and Durgut, S. (2016). Training Performance Evaluation Using the 360-Degree Feedback Method, in 19th Eurasian Business and Economics Society (EBES) Conference. Istanbul, 623-627. https://doi.org/10.13140/RG.2.1.3367.3843

Lunce, L. (2006). Simulations: Bringing the benefits of situated learning to the traditional classroom. Journal of Applied Educational Technology, 3(1), 37-45.

McDonald, A. (2020, Feb 17). 10 essential Soft Skills you need to get a job in film, games and design industries. The Rookies. Available at: https:// discover.therookies.co/2020/02/17/10-essential-soft-skills-you-need-to-get-a-job-infilm-games-and-design-industries/

Northern Illinois University Center for Innovative Teaching and Learning (NIU-CITL) (2012). Situated learning. Instructional guide for university faculty and teaching assistants. Available at: https://www.niu.edu/citl/ resources/guides/instructional-guide

Roach, K., Tilley, A. and Mitchell, J. (2018). How authentic does authentic learning have to be?. Higher Education Pedagogies, 3(1), 495-509. https:/ / doi.org/10.1080/23752696.2018.1462099

Shaltry, C., Henriksen, D., Lun Wu, M. and Dickson, P. (2013). Situated Learning with Online Portfolios, Classroom Websites and Facebook. TechTrends, 57(3), 20-25. https://doi.org/10.1007/s11528-013-0658-9

Stein, D. (1998). Situated Learning in Adult Education. ERIC Digest No. 195. 1-7. https:// files.eric.ed.gov/fulltext/ ED418250.pdf

Vyas, D., van der Veer, G. and Nijholt, A. (2012). Creative practices in the design studio culture: collaboration and communication. Cognition Technology \& Work, 15(4), 1-29. https:// doi.org/10.1007/s10111-012-0232-9

Wesselink, R., de Jong, C. and Biemans, H. J. A. (2010). Aspects of Competence-Based Education as Footholds to Improve the Connectivity Between Learning in School and in the Workplace. Vocations and Learning, 3, 1938. https://doi.org/10.1007/s12186-009-9027-4 